\title{
Atypical cause of stroke in an 18 years old female
}

\author{
Md. Rashedul Islam, Tanbin Rahman², Rumana Habib ${ }^{3}$, Aminur Rahman, Nirmalendu Bikash Bhowmik 5 \\ Md. Amirul Haque ${ }^{6}$
}

\begin{abstract}
Central nervous system (CNS) tuberculous meningitis is a progressive disease that presents in many ways. CNS TB is encountered frequently in areas of high prevalence of tuberculosis and dissemination is common. An 18 year old female presented with complaints of headache, low grade fever \& double vision. We found cranial nerve palsy \& focal neurological signs during examination. Work up revealed cerebral spinal fluid (CSF) study consistent with acute lymphocytic meningitis. Magnetic resonance imaging (MRI) revealed multiple tuberculomas with gadolinium enhancement \& cerebral infarction on basal ganglia. Given the characteristic CSF and MRI finding for Tuberculosis (TB), positive MT \& choroidal tubercle on fundoscopy, ischemic stroke due to tubercular meningitis is made. The patient showed significant improvement after anti tuberculosis therapy was begun. CNS TB is a treatable disease but can be fatal if not detected or treated. Clinicians should be aware of key clinical features of TB meningitis, and maintain a high level of suspicion when patients present with focal neurological signs.
\end{abstract}

Key Words: Ischemic stroke, Tuberculous meningitis.

\section{Introduction:}

Strokes in young adults are relatively uncommon; the disorder usually occurs in the middle-aged and elderly. The National Survey of Stroke revealed that only $3.7 \%$ of all strokes occurred in patients' aged 15-45 years. ${ }^{1}$ The etiologic and prognostic features that characterize strokes in older persons may not apply to young adults. ${ }^{2}$ Central Nervous System (CNS) disease due to Mycobacterium tuberculosis accounts for $1-10 \%$ of all tuberculosis (TB) cases ${ }^{1}$, mostly affecting children. ${ }^{3}$ Tubercular Meningitis (TBM) is the most frequent presentation of CNS TB, with its most serious consequence being brain infarction. ${ }^{4}$ Most TBM associated brain infarcts are multiple, bilateral, symmetric, located in the basal ganglia, anterior thalamus, anterior limb and the genu of internal capsule. ${ }^{5,6}$ Cortical, sub-cortical white matter, brainstem and

1. Dr. Md. Rashedul Islam, MBBS, MRCP (UK), FCPS (Medicine), FACP(USA), Registrar, Department of Neurology, BIRDEM General Hospital.

2. Dr. Tanbin rahman, MBBS, Registrar, Medicine, Greenlife Medical College, Dhaka

3. Dr. Rumana Habib, MBBS, FCPS (Medicine), Assistant Professor, Department of Neurology, BIRDEM General Hospital

4. Dr. Aminur Rahman, MD, FACP (USA), MBBS, Consultant, Department of Neurology, BIRDEM General Hospital

5. Dr. Nirmalendu Bikash Bhowmik, MBBS, MD, Professor, Department of Neurology, BIRDEM General Hospital

6. Prof. Dr. Md. Amirul Haque, MBBS, FCPS, DCN(London), FACP(USA), FRCP(Glasgow), Professor \& Head, Department of Neurology, BIRDEM General Hospital

\section{Corresponding Author:}

Dr. Md Rashedul Islam

MBBS, FCPS, MRCP (UK), FACP (USA)

Registrar, Neurology

BIRDEM General Hospital, Dhaka, Bangladesh.

email: rashed2k2001@yahoo.com hindbrain involvement are less common..$^{5-8}$ Stroke in TBM can be ischemic or hemorrhagic ${ }^{9}$ and secondary to vasculitis or intimal proliferation or both, with or without thrombosis or spasms. Aneurismal dilatation, ruptured mycotic aneurism, granulomatous septic embolism and arteries being strangulated by inflammatory exudates have also been noted. ${ }^{5,6}$

Here, we report a case of a young female who developed stroke due to TBM secondary vasculopathy with brain infarction with tuberculoma.

\section{Case presentation:}

An 18 years old young lady presented in Neurology, BIRDEM with weakness of left side of body which was sudden on onset, associated with facial asymmetry, dysphagia, urinary retention, and diplopia. She also had history of headache which was global, continuous, dull aching, more in morning associated with irregular bouts of low grade fever. On examination, she had bilateral complete opthalmoplegia, right sided UMN VII ${ }^{\text {th }}$ nerve palsy, choroidal tubercle on fundoscopy. She had hypertonia, diminished muscle power, exaggerated reflexes, extensor plantar response on left side, hemiplegic gait $\&$ signs of meningial irritation. Initial laboratory investigations revealed hemoglobin $10.2 \mathrm{gm} / \mathrm{dl}$, leukocytosis of $13.78 \mathrm{th} / \mathrm{mm}^{3}$ with $78 \%$ neutrophils, ESR $78 \mathrm{~mm}$ in $1^{\text {st }}$ hour. Complete metabolic panel were within normal limits. Cerebral spinal fluid (CSF) study revealed WBC count of $250 / \mathrm{mm}^{3}$ with $90 \%$ lymphocytes, glucose $4.2 \mathrm{mg} / \mathrm{dl}$, protein $109 \mathrm{mg} / \mathrm{dl}$, and was clear in character. Chest x-ray was normal and non-contrast computed tomography (CT) of head revealed cerebral infarction involving right basal ganglia. Magnetic resonance imaging (MRI) of brain revealed acute right basal ganglia infarction with multiple ring enhancing lesions involving both basal ganglia (Fig $1 \& 2$ ). Given the characteristic finding of the CSF and MRI, Mantoux Test (MT) was done \& it was 22 $\mathrm{mm}$ after 72 hours. Finally she was diagnosed as tubercular meningitis with ischemic stroke \& managed with anti 
tubercular drugs. She was clinically improved after 1 month follow up.

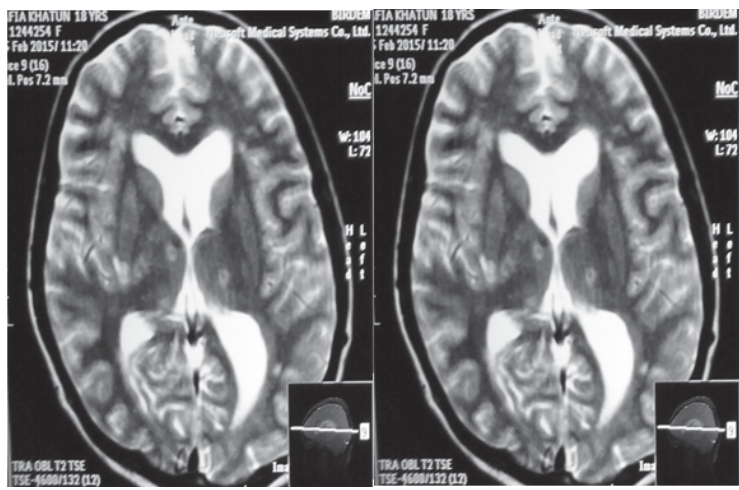

Figure 1 \& 2: MRI of brain showing acute right basal ganglia infarction with multiple ring enhancing lesions involving both basal ganglia

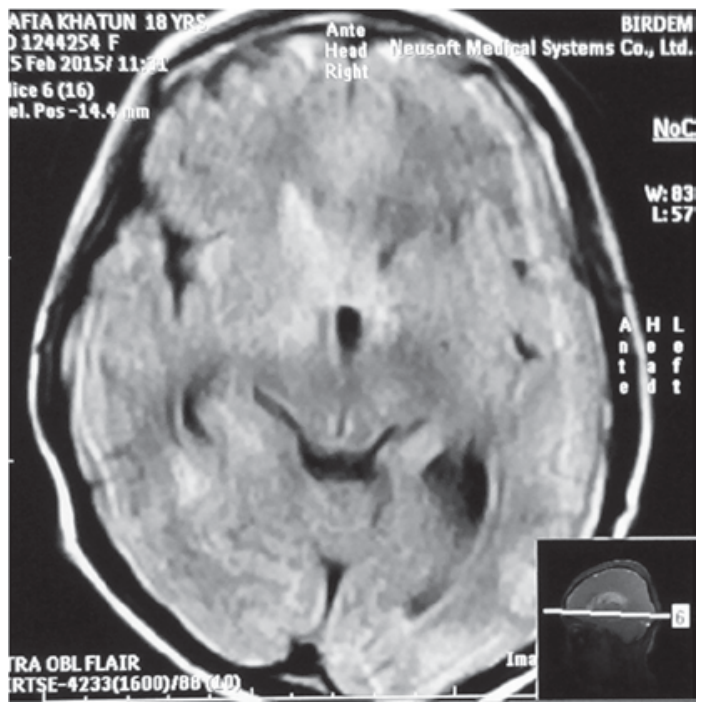

Figure 3 : MRI of brain (FLAIR) shows acute infarction on right basal ganglia

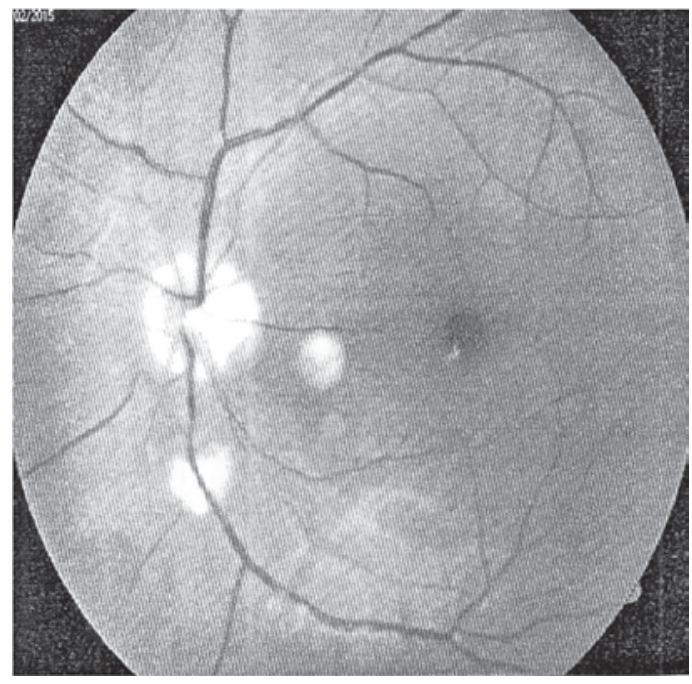

Figure 4: Choroidal tubercle on color fundus photograph

\section{Discussion:}

CNS TB is encountered frequently in areas that continue to have high prevalence of tuberculosis and dissemination is very common in children and young adults. ${ }^{10,11}$ Tuberculous meningitis develops most commonly from chronic reactivation in patients with immune deficiency secondary to aging, malnutrition, alcoholism, malignancy, or HIV infection. Clinical features of TB meningitis commonly consist of a series of phases, beginning with sub acute fever, malaise, and personality changes. This may last for two- three weeks and if unrecognized will progress to a meningitic phase. Meningitic phase has more pronounced neurologic features such as confusion, headache, lethargy, and focal cranial nerve deficits. The final phase is the paralytic phase consisting of stupor, coma, seizures, and possibly stroke. ${ }^{10-15}$ Typical CSF shows elevated protein usually greater than 100 , low glucose $(80 \%$ less than $45 \mathrm{mg}$ 'dl) and elevated WBC (between 100 and 500 cells/microL) with lymphocytic pleocytosis. ${ }^{13-17}$ Spillage of tubercular protein into the subarachnoid space causes an inflammatory reaction most commonly seen in the base of the brain. If the inflammation goes unchecked it will produce a fibrous mass that may encase cranial nerves and penetrate into vessels leading to vasculitis and resulting in infarction. Multiple lesions may be common allowing for a variety of stroke like symptoms most commonly in the basal ganglia, pons, and cerebellum. ${ }^{14.17} \mathrm{CT}$ and MRI tend to have characteristic findings of basilar enhancement and edema with possible infarction and hydrocephalus. ${ }^{14,18,19}$

In our case patient had headache, low grade fever and focal neurological symptoms. On examination she had cranial nerve palsy, upper motor neuron signs \& characteristic choroidal tubercle on fundoscopy. MRI showed multiple tuberculomas with gadolinium enhancement \& cerebral infarction on basal ganglia. Cerebrospinal fluid examination is the cornerstone of TBM diagnosis and we found typical findings. MT was strongly positive and we started anti-TB treatment immediately. The value of anti-inflammatory treatment with corticosteroids ${ }^{20-22}$ in preventing infarction in TBM is controversial and the role on anti-TB therapy on the development of stroke is also not well defined. ${ }^{23,}{ }^{24}$ In a prospective, randomized study, in 2010, reported a reduction rate of stroke and mortality in a subgroup of patients with TBM randomized to receive aspirin daily. ${ }^{25}$ So aspirin was prescribed in our patient.

\section{Conclusion:}

In conclusion, TBM and stroke is a diagnostic challenge \& difficult to treat. Moreover, drug interactions and their side effects add levels of complexity. TBM should be included in the differential diagnosis patients with stroke and TBM treatment needs be started as soon as possible before the onset of vasculopathy. 


\section{References:}

1. Walker AE, Robins M, Weinfeld FD. The National Survey of Stroke: clinical findings. Stroke 1981; 12 (2 Pt 2 Suppl 1): 113-44.

2. Adams HP Jr, Butler MJ, Biller J, Toffol GJ. Nonhemorrhagic cerebral infarction in young adults. Arch Neurol 1986; 43:793-96.

3. Rock RB, Olin M, Baker CA, Molitor TW, Peterson PK. Central nervous system tuberculosis and clinical aspects. Clin Microbiol Rev 2008; 21: 243-61.

4. Misra UK, Kalita J, Maurya PK. Stroke in tuberculous meningitis. J Neurol Sci. 2011; 303: 22-30.

5. Lammie GA, Hewlett RH, Schoeman JF, Donald PR. Tuberculous cerebrovascular disease. A review. J Infect 2009; 59: 156-66.

6. Katrak SM, Shembalkar PK, Bijwe SR, Bhandarkar LD. The clinical, radiological and pathological profile of tuberculosis meningitis in patients with and without human immunodeficiency virus infection. J Neurol Sci 2000; 181: 118- 26.

7. Garg RK, Sinha MK. Tuberculous meningitis in patients infected with human immunodeficiency virus. J Neurol 2011; 258: 3-13.

8. Vinnard C, Macgregor RR. Tuberculous meningitis in HIV infected individuals. Curr HIV/AIDS Rep 2009; 6 (3): 139-45.

9. Kalita J, Misra KU, Nair PP. Predictors of stroke and its significance in the outcome of tuberculous meningitis. J Stroke Cerebrovascul Dis. $2009 ; 18$ (4): 251-58

10. Farer LS, Lowell AM, Meador MP: Extra pulmonary tuberculosis in the United States. Am J Epidemiol 1979; 109: 205-17.

11. Kent SJ, Crowe SM, Yung A et al. Tuberculous meningitis: a 30 year review. Clin Infect Dis, 1993; 17: 987-94.

12. American Thoracic society, Centers for Disease Control and Prevention. Targeted tuberculin testing and treatment of latent tuberculosis infection. Am J Respir Crit Care Med 200: 161 (suppl): S221-247.

13. Chan KH, Cheung RT, Lee R, Mak W. Cerebral infarcts complicating tuberculous meningitis. Cerebrovasc Dis 2005; 19: 391-95.
14. Farinha NJ, Razali KA, Holzel H, Novelli VM. Tuberculosis of the central nervous system: a 20 year survey. J Infect 2000; 41: 61-8.

15. Kaneko K, Onodera O, Miyatake T, Tsuji S. Rapid diagnosis of tuberculous meningitis by polymerase chain reaction (PCR). Neurology 1990; 40: 1617-18.

16. Dastur DK, Manghani DK, Udani PM. Pathology and pathogenetic mechanisms in neurotuberculosis. Radiol Clin North Am 1995; 33 $733-52$.

17. Ozates M, Kemaloglu S, Gurkan U et al. CT of the brain in tuberculous meningitits. A review of 289 patients. Acta Radiol 2000; 41: 13-17.

18. Menzies D. Interpretation of repeated tuberculin test. Boosting, conversion, and reversion. Am J Respir Crit Care Med 1999; 159: $15-21$.

19. Bernaerts A, Vanhoenacker FM, Parizel PM et al. Tuberculosis of the central nervous system: overview of neuroradiological findings. Eur Radiol 2003; 13: 1876-90.

20. Marais S, Thwaites G, Schoeman JF, Misra UK, Prasad K, Donald $P$ et al. Tuberculous meningitis: a uniform case definition for use in clinical research. Lancet 2010; 10: 803-12.

21. Garg RK. Tuberculous meningitis. Acta Neurol Scand 2010; 122: 75-90. PMid:20055767

22. Thwaites GE, Fisher M, Hemingway C, Scott G, Solomon T, Innes $\mathrm{J}$. British infection society guidelines for diagnosis and treatment of tuberculosis of the central nervous system in adults and children. $\mathrm{J}$ Infect 2009; 59: 167-87.

23. Lammie GA, Hewlett RH, Schoeman JF, Donald PR. Tuberculous cerebrovascular disease. A review. J Infect 2009; 59: 156-66.

24. Lee MH, Yang HI, Wang CH, Jen CL, Yeh SH, Liu C-J et al. Hepatits $\mathrm{C}$ virus infection and increased risk of cerebrovascular diseases. Stroke. 2010 Dec; 41(12): 2894-900.

25. Shukla R, Abbas A, Kumar P, Gupta RK, Jha S, Prasad KN. Evaluation of cerebral infarction in tuberculous meningitis by diffusion weighted imaging. J Infect. 2008; 57: 298-306. 